\title{
Short vertical-wavelength inertia-gravity waves generated by a jet-front system at Arctic latitudes - VHF radar, radiosondes and numerical modelling
}

\author{
A. Réchou ${ }^{1}$, S. Kirkwood ${ }^{2}$, J. Arnault ${ }^{2}$, and P. Dalin ${ }^{2}$ \\ ${ }^{1}$ Laboratoire de l'Atmosphère et des Cyclones, La Réunion University, Réunion Island, France \\ ${ }^{2}$ Swedish Institute of Space Physics, Box 812, 98128 Kiruna, Sweden
}

Correspondence to: A. Réchou (arechou@univ-reunion.fr)

Received: 27 September 2013 - Published in Atmos. Chem. Phys. Discuss.: 2 December 2013

Revised: 26 May 2014 - Accepted: 26 May 2014 - Published: 3 July 2014

\begin{abstract}
Inertia-gravity waves with very short vertical wavelength $\left(\lambda_{z} \leq 1000 \mathrm{~m}\right)$ are a very common feature of the lowermost stratosphere as observed by the $52 \mathrm{MHz}$ radar ESRAD (Esrange MST radar) in northern Scandinavia $\left(67.88^{\circ} \mathrm{N}, 21.10^{\circ} \mathrm{E}\right)$. The waves are seen most clearly in radar-derived profiles of buoyancy frequency $(N)$. Here, we present a case study of typical waves from 21 February to 22 February 2007. Good agreement between $N^{2}$ derived from radiosondes and by radar shows the validity of the radar determination of $N^{2}$. Large-amplitude wave signatures in $N^{2}$ are clearly observed by the radar and the radiosondes in the lowermost stratosphere, from $9 \mathrm{~km}$ to $14-16 \mathrm{~km}$ height. Vertical profiles of horizontal wind components and potential temperature from the radiosondes show the same waves. Mesoscale simulations with the Weather Research and Forecasting (WRF) model are carried out to complement the analysis of the waves. Good agreement between the radar and radiosonde measurements and the model (except for the wave amplitude) shows that the model gives realistic results and that the waves are closely associated to the upper-level front in an upper-troposphere jet-front system. Hodographs of the wind fluctuations from the radiosondes and model data show that the waves propagate upward in the lower stratosphere confirming that the origin of the waves is in the troposphere. The observations and modelling all indicate vertical wavelengths of $700 \pm 200 \mathrm{~m}$. The radiosonde hodograms indicate horizontal wavelengths between 40 and $110 \mathrm{~km}$ and intrinsic periods between 6 and $9 \mathrm{~h}$. The wave amplitudes indicated by the model are however an order of magnitude less than in the observations. Finally, we show that the profiles of $N^{2}$
\end{abstract}

measured by the radar can be used to estimate wave amplitudes, horizontal wavelengths, intrinsic periods and momentum fluxes which are consistent with the estimates from the radiosondes.

\section{Introduction}

Gravity and inertia-gravity waves (IGWs) play a very important role in the physics of the stratosphere and mesosphere. For example, in the high-latitude stratosphere, large vertical displacements induced by mountain waves can reduce local temperatures by up to $10 \mathrm{~K}$ and can lead to the formation of polar stratospheric clouds in winter (Dörnbrack et al., 2002). Gravity waves (GWs) also have a strong influence on the general circulation of the atmosphere (Holton, 1992) by the transport of momentum from the lower levels to the middle and upper levels of the atmosphere (Fritts and Alexander, 2003). In this way, they change the dynamics and thermal balance of the atmosphere. Since the horizontal and vertical scales of most GWs are too small to be explicitly resolved in atmospheric general circulation models (GCMs), the waves must be parameterized in the models. The uncertainty of such parameterizations causes substantial uncertainties in the models (Morgenstern et al., 2010). A detailed understanding of wave-generation processes and the spectrum of waves that they produce is therefore crucial for the accuracy of global models.

The properties of GWs are very dependent on the processes that cause them. Known sources of waves include 
topographic effects and convection (Smith, 1979; Lilly et al., 1982; Bretherton and Smolarkiewitcz, 1989; Shutts and Gray, 1994; Fritts and Alexander, 2003, and specifically at the location considered in the present study, Kirkwood et al., 2010b; and Réchou et al., 2013), fronts (Eckermann and Vincent, 1993; Griffiths and Reeder, 1996), diabatic heating (Hooke, 1986), wind shear (Rosenthal and Lindzen, 1983; Fritts, 1982; Lott et al., 2009) and instability of the uppertropospheric jet (Ucellini and Koch, 1987; Zülicke and Peters, 2008). In the present study, we focus on IGWs generated by the jet at high latitudes.

A number of observational and modelling studies have suggested that the polar jet stream (in the upper-troposphere at mid- or high latitudes) can generate IGWs. For example, Plougonven et al. (2003), using a very large number of radiosoundings at midlatitudes $\left(\sim 40^{\circ} \mathrm{N}\right)$ over the North Atlantic, showed IGW packets propagating upward in the lower stratosphere and downward in the midtroposphere, closely correlated in space with regions of strongest curvature and highest wind speeds in an upper-troposphere jet. The waves had short vertical wavelengths, generally $2-3 \mathrm{~km}$, small amplitude, typically $2-4 \mathrm{~ms}^{-1}$ in the stratosphere, and low intrinsic frequency, between $f$ and $2 f$ (where $f$ is the Coriolis parameter). In later modelling work (Plougonven and Snyder, 2007), they were able to reproduce the main characteristics of the wave generation by the jet stream. Lane et al. (2004) used dropsondes in the vicinity of an intense jet-front system near $40^{\circ} \mathrm{N}$ over the Pacific to study the associated IGWs. They also found short vertical wavelengths, from 1 to $2.3 \mathrm{~km}$. Using 8 years of observations from the UK MST (Mesosphere-Stratosphere-Troposphere) radar at Aberystwyth $\left(52^{\circ} \mathrm{N}\right)$, Vaughan and Worthington (2007) determined the occurrence and properties of long-period quasimonochromatic oscillations in the wind vector identified with IGWs. They found that the waves had typical amplitudes $1-2 \mathrm{~ms}^{-1}$, vertical wavelengths around $2 \mathrm{~km}$, and that waves with $6-8 \mathrm{~h}$ (ground-based) periods were strongly correlated with the jet stream. In the stratosphere, the waves were dominated by upward energy propagation (clockwise rotation of the wind vector) and in the troposphere by downward propagation, consistent with the dominant source for IGWs being at tropopause level. Over northern Germany $\left(54^{\circ} \mathrm{N}\right)$, Zülicke and Peters (2008) showed combined observations and modelling studies (MM5 mesoscale model) of jet-generated waves. They also include the Lagragian Rossby number as an indicator for potential wave-generation regions. At high southern latitudes, Guest et al. (2000) examined high-resolution upper-air soundings of wind and temperature released from Macquarie Island $\left(54^{\circ} \mathrm{S}\right)$. They found waves with vertical wavelengths between about 1 and $7 \mathrm{~km}$ and intrinsic frequency between $f$ and $2 f$. They used a ray-tracing model to show that waves propagating into the lower stratosphere probably had their source in a jet-front system to the $\mathrm{SW}$ of the island. Finally, in a recent study using a number of long-duration balloon flights at very high latitudes $\left(60-90^{\circ} \mathrm{N}\right.$ and S), IGWs with non-orographic sources, suggested to be jet-front systems, were found to be of comparable importance to orographic waves regarding their contribution to momentum flux in the lower stratosphere (Vincent et al., 2007).

Measurements from satellites are today often considered to offer the best possibility for global, climatological studies of GWs. Certainly, characterization of GWs has been much improved in recent years, particularly in polar regions where ground-based observations are relatively sparse, thanks to high-resolution satellite observations. Both climatologies and case-studies have been made using data from satellite instruments (e.g. Atmospheric Infrared Sounder/High Resolution Dynamics Limb Sounder, Alexander and Teitelbaum, 2011; National Oceanic and Atmospheric Administration Advanced Microwave Sounding, Wu, 2004; and GPS radio occultation, Hei et al., 2008). However, the lower limit of vertical wavelengths which can be resolved by such satellite measurements is $2-4 \mathrm{~km}$ (Preusse et al., 2008) which is not sufficient to study the jet-related IGWs as observations show that they can have vertical wavelengths of less than $2 \mathrm{~km}$. Another possibility might be to use modelling, as in case studies (e.g. O'Sullivan and Dunkerton, 1995; Wu and Zhang, 2004; Zhang, 2004; Plougonven and Snyder, 2007; Zülicke and Peters, 2008). However, it is not practicable to use such modelling for climatological studies due to the necessity of both high resolution and large domain sizes.

In this paper, we examine whether IGWs from the uppertroposphere jet can be observed and characterized by the VHF radar ESRAD (Esrange MST radar), located near Kiruna in northern Sweden $\left(67.88^{\circ} \mathrm{N}, 21.10^{\circ} \mathrm{E}\right)$. This radar has been operating in a mode capable of resolving perturbations associated with short-vertical-wavelength $\left(\lambda_{z}>300 \mathrm{~m}\right)$ GWs, continuously since 2005 . The radar is less powerful than those generally used for gravity-wave climatologies based on fluctuations in horizontal winds. The wind perturbations associated with jet-source IGW's are expected to be very small (a few metres per second as observed in the radiosonde data) and cannot be reliably determined using high-vertical-resolution measurements at ESRAD. However, buoyancy frequency $(N)$ can be measured with high accuracy (see Appendix) and shows strong wave signatures, particularly for short vertical wavelengths (Kirkwood et al., 2010a, b; Réchou et al., 2013). The radar is located, most of the time, poleward of, but close to, the jet stream associated with the northern Atlantic storm tracks; so there is the potential for climatological study of the characteristics of jetinduced waves. In this first step, we make a case study. We analyse the characteristics of GWs obtained by the radar and by collocated radiosondes from 21 to 22 February 2007 . To complement the observations, simulations with the high resolution non-hydrostatic mesoscale model WRF (Weather Research and Forecasting Model; Skamarock and Klemp, 2008) are made and the characteristics of the waves obtained by the model are compared to the observations. To determine the characteristics of the waves, we use spectral analysis (for 
observations and model), hodograph analysis (for radiosonde and model winds) and, for the radar data, the amplitude of the perturbations in $N^{2}$ and the assumption that the wave amplitudes are at the wind-shear instability limit (Gubenko et al., 2008, 2011).

\section{Methods}

\subsection{VHF radar}

We use measurements from the $52 \mathrm{MHz}$ radar ESRAD, located at Esrange (European space range; $67.88^{\circ} \mathrm{N}, 21.10^{\circ} \mathrm{E}$ ) near Kiruna in northern Sweden. The radar has a peak transmitter power of $72 \mathrm{~kW}$ and an antenna array consisting of 284, 5-element Yagi antennas spread over an area of $72 \mathrm{~m} \times 64 \mathrm{~m}$ and pointing vertically. Echo power and Doppler shift (vertical wind) are measured using the whole array. The array is divided into 6 sub-arrays to allow horizontal winds and turbulence parameters to be determined using interferometry. The radar in general provides information on the dynamic state of the atmosphere such as winds, waves, turbulence and layering, from about 1 to $20 \mathrm{~km}$ altitudes in the troposphere and lower stratosphere. Further technical details can be found in Chilson et al. (1999), updated in Kirkwood et al. (2010a).

The radar usually (since 2005) operates in two modes with vertical sampling intervals of 150 and $600 \mathrm{~m}$, respectively. The mode with $150 \mathrm{~m}$ sampling is used here. Each sample corresponds to a Gaussian-weighted average over a height interval with half-power width of about $200 \mathrm{~m}$. For heights above about $5 \mathrm{~km}$, this mode provides accurate estimates only of echo power and Doppler, not of horizontal wind. $N$ is derived form echo power $\left(P_{r}\right)$ by

$N^{2}=A z \exp (z / H) P_{r}^{1 / 2}$,

where $z$ is the height from which the echo is returned, $H$ is the atmospheric scale height and $A$ is a calibration factor which can be found either by technical calibration of the radar or by comparison of the derived profile of $N^{2}$ with co-located radiosoundings (in the present case we use radiosoundings and both $P_{r}$ and $A$ are in arbitrary units. For a discussion of the value of A when $P_{r}$ is in watts, see Kirkwood et al., 2010a).

Equation (1) is strictly applicable only in the absence of humidity, i.e. in the stratosphere. However, previous studies have shown that the method gives accurate estimates of $N^{2}$ in both the upper troposphere and the lower stratosphere (e.g. Kirkwood et al., 2010a; Arnault and Kirkwood, 2012).

In this study, we use fluctuations in $N^{2}$ rather than the more usual wind fluctuations measured by the radar to characterize the waves since this can be measured with higher accuracy in the relevant conditions. A more detailed discussion of this issue can be found in the Appendix.
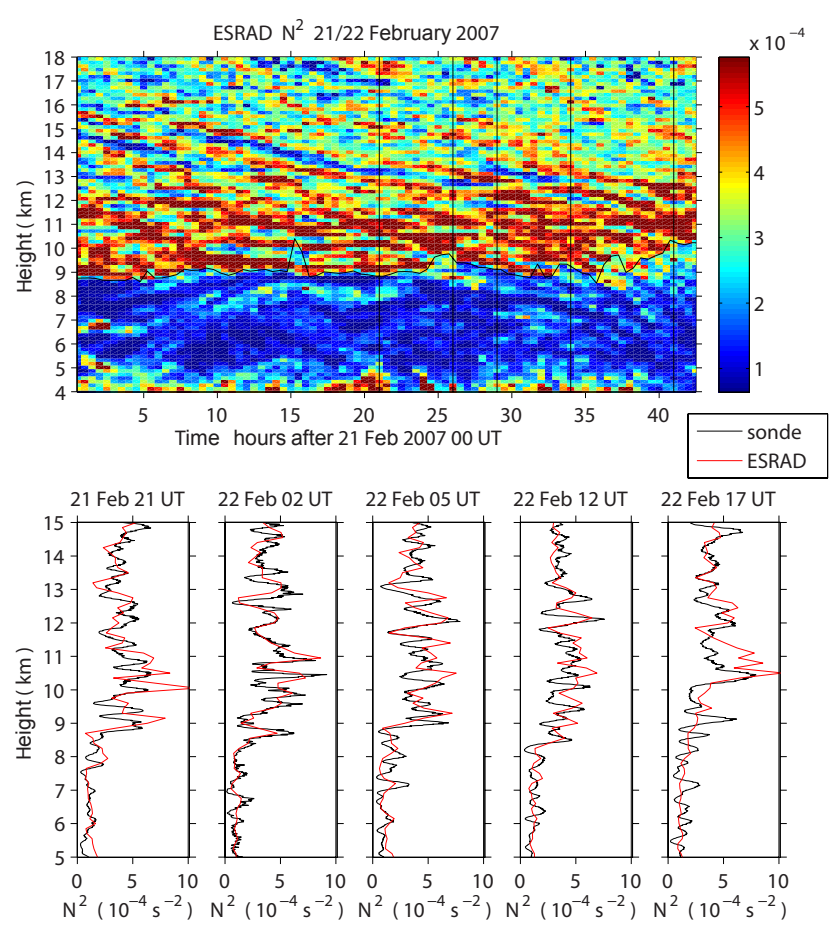

Figure 1. Top panel: time-height diagram of squared buoyancy frequency, $N^{2}$ (in s ${ }^{-2}$; colour), from ESRAD observations. The horizontal axis gives the time in hours from 00:00 UTC 21 February 2007 to 18:00 UTC 22 February 2007, and the vertical axis gives the height in kilometres. The scale for $N^{2}$ is given by the coloured bar on the right of the top row. Lower panels: comparison of profiles of $N^{2}$, between radar (red) and radiosondes (black) launched at the radar site at 21:00 UTC 21 February 2007, 02:00, 05:00, 12:00 and 17:00 UTC 22 February 2007. Vertical black lines on the top panel show the times of the radiosonde launches.

The period 21/22 February 2007 was chosen for this study due to the presence of inertia-gravity wave signatures which are typical for this site (clear descending wave fronts with short vertical wavelength, $\lambda_{z} \leq 1 \mathrm{~km}$, and long ground-based period, $T_{\mathrm{g}}>6 \mathrm{~h}$ ) and the availability of a number of closely collocated radiosonde measurements with high vertical resolution. The top panel in Fig. 1 shows the radar measurements of $N^{2}$. The thin black line at around $9 \mathrm{~km}$ height follows the maximum vertical gradient in $N^{2}$ and is the radar-based estimate of the tropopause height. Further analysis of the radar measurements is considered in Sect. 5.

\subsection{Radiosondes}

Five radiosondes were launched from Esrange, at 21:00 UTC (universal time coordinated) on 21 February 2007 and at 02:00, 05:00, 12:00 and 17:00 UTC on 22 February 2007. The raw data were sampled at $2 \mathrm{~s}$ intervals, resulting in an uneven vertical interval, which varies from 6 to $9 \mathrm{~m}$. For the calculation of $N^{2}$, the raw values of potential temperature were smoothed to have the same height resolution $(200 \mathrm{~m})$ as the 
radar data. The lower panels in Fig. 1 compare $N^{2}$ from the sondes with the values measured by the radar. Profiles from the radar represent $1 \mathrm{~h}$ averages following the sonde launch. The vertical lines on the top panel indicate the times of launch. The value of the proportionality constant $A$ in Eq. (1) has been found by comparison with the sonde at 02:00 UTC on 22 February, so there is necessarily good agreement in the average value of $N^{2}$ for that sonde. Fluctuations about the average are independently measured by the two techniques. On this occasion, the sondes drifted north or northwest after launch reaching horizontal distances of $20-35 \mathrm{~km}$ at the height of the tropopause. They then drifted back toward the radar, passing within $3-20 \mathrm{~km}$ at $18-20 \mathrm{~km}$ height. The two sondes at 02:00 and 05:00 UTC on 22 February passed closest to the radar beam in the lower stratosphere - coming as close as 3 and $5 \mathrm{~km}$, respectively. The agreement between the radar-derived and the sonde-derived $N^{2}$, even as regards small fluctuations in the height profiles, is generally good, particularly for those two sondes. Further analysis of the radiosonde measurements is considered in Sect. 5.

\subsection{WRF model}

The WRF model (Skamarock and Klemp, 2008) was configured for this case study as a non-hydrostatic model with a single domain $2700 \mathrm{~km} \times 2400 \mathrm{~km}$ in area covering Scandinavia and western Russia, between about $50-75^{\circ} \mathrm{N}$ and $10-50^{\circ} \mathrm{E}$. Conditions at the outer boundaries were defined by ECMWF (European Centre for Medium-Range Weather Forecasts) model-level analysis. In the model domain, a horizontal resolution of $6 \mathrm{~km}$ was used, together with 251 vertical levels between the surface and $24 \mathrm{~km}$ height. The corresponding vertical interval is $90-100 \mathrm{~m}$ above $800 \mathrm{~m}$ height, and $26-89 \mathrm{~m}$ below that. A $5000 \mathrm{~m}$ thick damping layer was used at the top of the model domain to prevent spurious wave reflections. Convection is explicit and microphysics is parameterized with the three-class liquid and ice hydrometeors scheme of Hong et al. (2004). The modelled values of $N^{2}$, for the location of the ESRAD radar are shown in Fig. 2, for the same time interval as the radar data shown in Fig. 1. It can be seen that the morphology of what appear to be the shortvertical-wavelength wave fronts, seen in Fig. 1, is reproduced well by the model, although the amplitudes in the model are clearly smaller. It is also observed in the fluctuations of $N^{2}$ corresponding to the times of each sonde.

In an earlier paper (Réchou et al., 2013), we have reported observations and WRF modelling of the period 18-20 February 2007. In that study, several model runs were made both with and without orography, and with and without clouds. The modelling was continued up to the end 22 February, although only the first part (waves of convective origin) was reported in Réchou et al. (2013). The waves we focus on in the present study appeared in model runs with or without mountains and with or without clouds, so their cause lies in the larger-scale wind, pressure and temperature fields (from
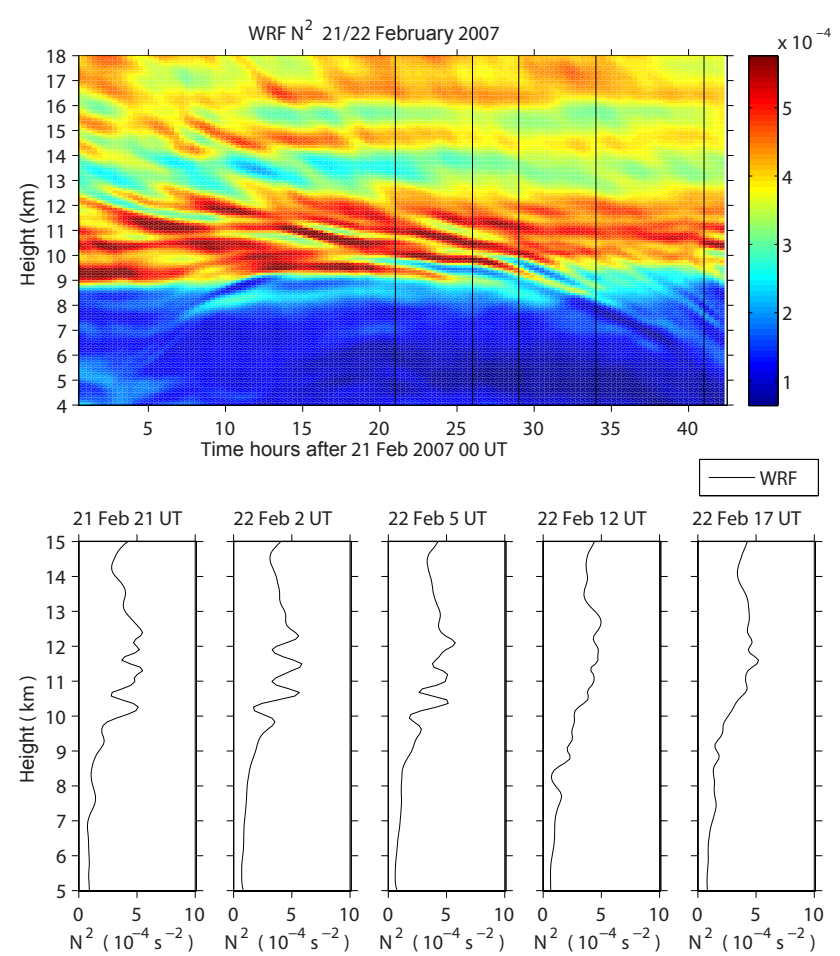

Figure 2. Time-height diagram of $N^{2}$ (in $\mathrm{s}^{-2}$, colours), from the WRF model experiment (same time and height axes as Fig. 1). Profiles of $N^{2}$ obtained by the WRF data at 21:00 UTC 21 February 2007, 02:00, 05:00, 12:00 and 17:00 UTC 22 February 2007, corresponding to the radiosonde launches.

ECMWF) which drive the WRF model. For the present study, the area of the model domain was extended to cover all of Scandinavia and the orography was included. It can also be mentioned that the WRF model has been previously used to study spontaneous generation of inertia-gravity waves in idealized jet/front conditions, e.g. by Plougonven and Snyder (2007), so it is likely suitable for the task.

Model results are discussed in more detail in Sects. 3-5.

\section{Synoptic situation}

Figure 3 presents the synoptic situation from 00:00 UTC on 20 February 2007 to 00:00 UTC on 22 February 2007, each $24 \mathrm{~h}$, computed with ECMWF analyses at $8.5 \mathrm{~km}$ altitude, in order to be close to the centre of the jet (Lane et al., 2004) and in the upper part of the troposphere. On 20 February, the location of ESRAD is affected by strong cyclonic winds related to the lower pressure to the east, and on 21 and 22 February by anticyclonic winds due to the high pressure to the north. Strong west-northwesterly winds are seen across the southern part of Scandinavia, with a region of strong curvature in this jet at 00:00 UTC on 21 February, moving further east by 22 February. Figure 4 shows Advanced Very High Resolution Radiometer (AVHRR) images taken by the polar 
orbiting NOAA-17 satellite in the thermal infrared (10.3$11.3 \mu \mathrm{m}$ ) channel 4 at 01:35 UTC on 20 February, 01:24 UTC on 21 February and 01:14 UTC on 22 February 2007 (from http://www.sat.dundee.ac.uk), i.e. close to the times of the ECMWF analyses in Fig. 3. We particularly draw attention to the band of clouds stretching across the north of Scotland and the south of Scandinavia, with a sharp border to the north indicating a NW-SE aligned front at the lower levels, below the jet stream shown in Fig. 3. The cloud images also show the progression of the system eastward over the course of the study interval.

Figures 5 and 6 show vertical and horizontal (at $12 \mathrm{~km}$ altitude) cross sections of wind and $N^{2}$ from the WRF model results, at 00:00 UTC on 21 and 22 February, respectively. The vertical cross sections are taken along two lines, marked $\mathrm{A}-\mathrm{B}$ and $\mathrm{C}-\mathrm{B}$ on the horizontal cross section. The western line $\mathrm{A}-\mathrm{B}$ provides a cross section through the radar location (marked by the vertical line on the left-hand panels and by the circle and letter "E" on the horizontal cross sections); the eastern line $\mathrm{C}-\mathrm{D}$ intersects the region of highest wind speed in the jet. The vertical sections clearly shows the jet, between 5 and $12 \mathrm{~km}$ altitude, in the southern part of each cross section. The tropopause (boundary between low and high values of $N^{2}$ ) is at about $12 \mathrm{~km}$ altitude on the equatorward side of the jet, and around $10 \mathrm{~km}$ on the poleward side. In A-B the jet has maximum strength at 00:00 UTC on 21 February, and has almost disappeared by 00:00 UTC on 22 February. A sharp front (sloping layer of high $N^{2}$ below about $10 \mathrm{~km}$ ) separates stronger winds to the south from slower winds to the north. This front coincides with the sharp poleward boundary in the clouds (Fig. 4) at about $5 \mathrm{~km}$ altitude and continues upwards to the tropopause, reaching the tropopause at $65-67^{\circ}$ latitude in $\mathrm{A}-\mathrm{B}, 55^{\circ}$ in $\mathrm{C}-\mathrm{D}$.

Finally, we note that the horizontal cross sections at $12 \mathrm{~km}$ altitude in Figs. 5 and 6 show cyclonic (northwesterly) winds over the north of Scandinavia. Comparing with Fig. 3, this means that, at the location of ESRAD and further north, the wind on 21 and 22 February reversed direction or stalled between the lower part of the troposphere and the stratosphere. This means that any waves generated in the troposphere (e.g. orographic waves) would be blocked by the wind reversal, and would not propagate upwards to the stratosphere.

\section{Source of the waves in the lower stratosphere}

Figures 5 and 6 show signatures of several waves. Those most clearly related to the jet-front system are the wave fronts, sloping upwards towards the south, over the main axis of the jet, and sloping upwards towards the north poleward of the jet, parallel with the upper-level front. The latter start at about $10 \mathrm{~km}$ altitude in the region of strong wind shear between the jet axis and the upper level front. Similar patterns are seen in both vertical sections, A-B and C-D, but shifted a few degrees towards the south in $\mathrm{C}-\mathrm{D}$. The wave fronts par-
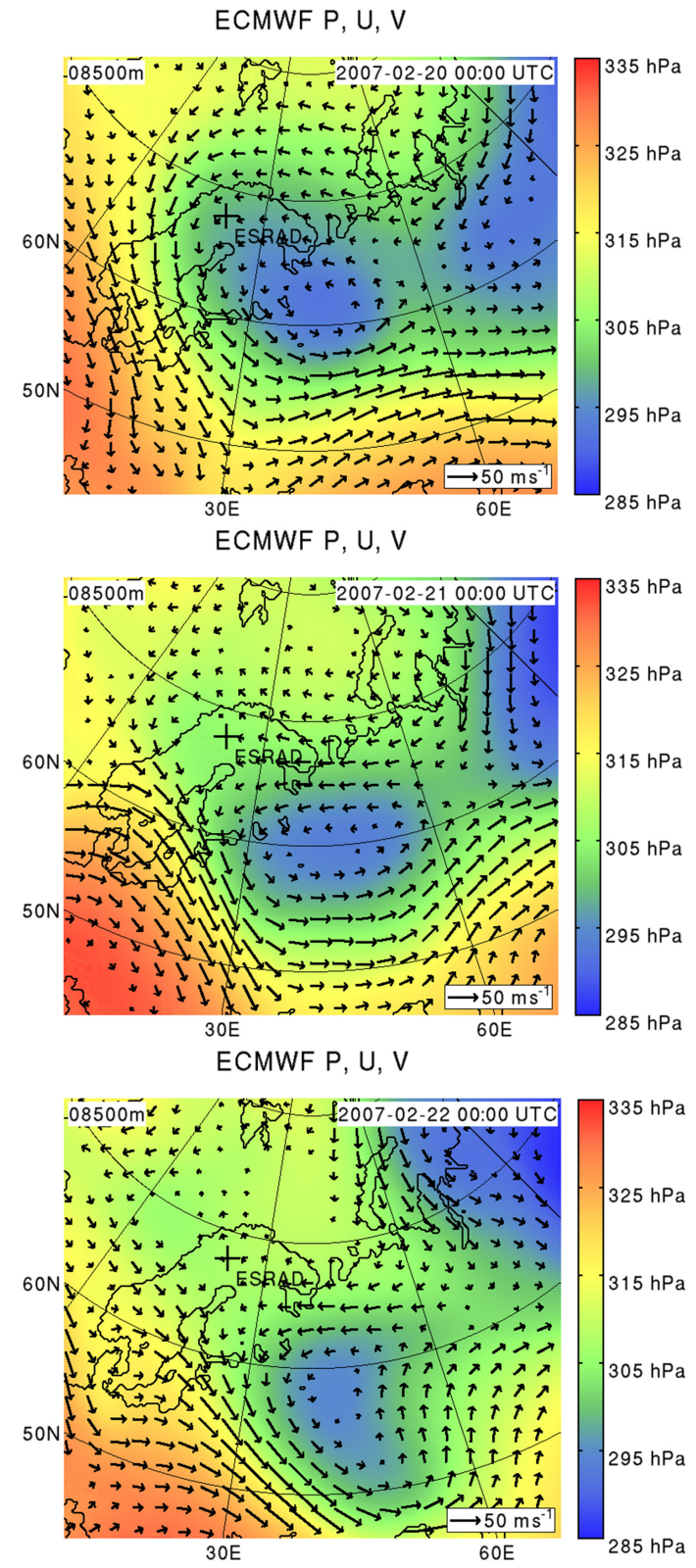

Figure 3. Horizontal cross sections at $8.5 \mathrm{~km}$ altitude of pressure (colour) in hectopascal and horizontal winds (arrows) in metres per second, from top to bottom, at 00:00 UTC on 20, 21 and 22 February 2007, from ECMWF analyses. The pressure scale is given by the coloured bar to the right, and the wind scale by the arrow at the bottom right corner of each panel. The black cross gives the location of ESRAD radar.

allel with the upper-level front are those seen at the radar location. It is clear from the horizontal cross section that these waves extend all along the poleward/eastward edge of the jet/front system from the north of Scandinavia to the vicinity of St Petersburg and Moscow. In the horizontal plane, the wave fronts are curved - they are close to the jet axis along 

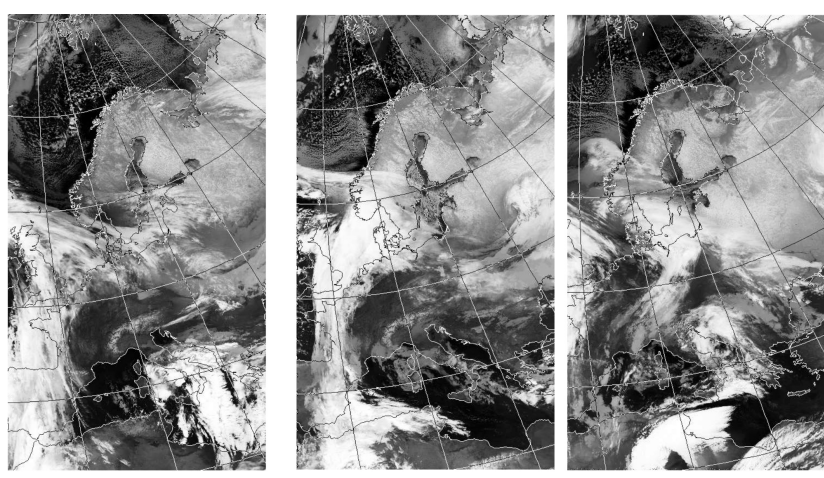

Figure 4. AVHRR images taken by the polar orbiting NOAA-17 satellite in the thermal infrared $(10.3-11.3 \mu \mathrm{m})$ channel 4, from left to right, at 01:35 UTC 20 February 2007, 01:24 UTC 21 February 2007 and 01:14 UTC 22 February 2007 (from http://www.sat. dundee.ac.uk).

$\mathrm{C}-\mathrm{D}$, but spread out further from the jet axis along A-B. This is likely a propagation effect and will be discussed later.

A complete set of figures, the same as Figs. 5 and 6, but for each 20 min from 12:00 UTC on 20 February to 24:00 UTC on 22 February is included in the Supplement. These clearly show the propagation of wave packets northward over the radar location, starting between the jet axis and the upper level front, propagating through the upward continuation of the front, and continuing further poleward.

It can also be noticed that the amplitude of the waves poleward of the jet/front is higher (more extreme values of $N^{2}$ are reached) along $\mathrm{C}-\mathrm{D}$ than along $\mathrm{A}-\mathrm{B}$. As we noted earlier, the simulations underestimate the amplitude at the radar location, so this may be a problem of the exact location of the frontal system, which may not be represented accurately enough by the ECMWF analysis which is used as the input to the simulation.

The waves directly over the main jet, tilting equatorward with height, are very similar in morphology and location (relative to the jet) to those found in the simulations by Lane et al. (2004), Plougonven and Snyder (2007) and Zülicke and Peters (2008). However, the waves propagating poleward from the poleward edge of the jet were not identified in those studies. It is clear from Figs. 5 and 6 that they have not only short vertical wavelengths (Fig. 2), but also rather short horizontal wavelengths of less than $100 \mathrm{~km}$. The horizontal resolution used by Plougonven and Snyder (2007), at best $25 \mathrm{~km}$, may not have been enough to resolve these waves. The simulations of Lane et al. (2004), on the other hand used slightly better horizontal resolution than current WRF modelling. In Fig. 7a of Lane et al. (2004), there are indications of weak waves in the lower stratosphere with wave fronts parallel to the upper-level front. At the same time, the waves directly over the jet core were stronger and were the focus of that study.

\section{Characteristics of the waves in the lower stratosphere}

In order to better understand the characteristics of the waves as they appear in the simulation and in the measurements, and their significance for momentum transport, we next examine the wave parameters - wavelength, frequency and amplitude.

\subsection{Vertical wavelengths}

To obtain the vertical wavelength, $\lambda_{z}$, we applied a classical multi-taper algorithm (Percival and Walden, 1993) to obtain the spectrum of the height profiles of buoyancy frequency from the radar (at the times of the radiosondes), the radiosondes and the model (at the radar location, at the times of the radiosondes). Results are illustrated in Fig. 7 for the times of the two sondes where the waves were clearest. Although the waves are clearest between 10 and $12 \mathrm{~km}$ altitude, we use the larger interval $10-14 \mathrm{~km}$ for this analysis to allow as many vertical wavelengths as possible to be included. As can also be seen in the time/height presentations of $N^{2}$ from the radar and from the model (Figs. 1, 2), the energy of the spectrum of fluctuations in $N^{2}$ from the model is lower than for the radar or the radiosondes. However, for each method there are clear spectral peaks for vertical wavelengths between 0.5 and $0.8 \mathrm{~km}$ (with a peak at around $600-700 \mathrm{~m}$ ). The results for $\lambda_{z}$ are summarized in Table 1, where the uncertainties are taken as the half-widths of the spectral peaks. The values for $\lambda_{z}$ are significantly shorter than found in previous studies (see introduction) where $1-2 \mathrm{~km}$ has typically been the shortest reported. However, previous studies have been at much lower latitudes, so we would not necessarily expect the same wave characteristics, and some previous studies (e.g. the radar-based results of Vaughan and Worthington, 2007) may not have been able to resolve such short wavelengths.

\subsection{Ground-based period}

The ground-based period is obtained from the time series of $N^{2}$ from the model and from the radar data over the time interval 21 February 05:00 UTC-22 February 09:00 UTC, at $12 \mathrm{~km}$ height. Both show a dominant peak at $7.5 \mathrm{~h}$ (Fig. 8), confirming further that the model reproduces the dominant waves seen by the radar.

The inertial period at the latitude of ESRAD is

$T_{f}=2 \pi / f=2 \pi /(2 \Omega \sin \varphi)$,

where $f$ is the Coriolis parameter at the radar latitude $\left(\varphi=67.88^{\circ} \mathrm{N}\right)$, and the angular rotation frequency of Earth $\Omega=7.292 \cdot 10^{-5} \mathrm{rads}^{-1}$. This yields $f=1.3511 \times 10^{-4} \mathrm{~s}^{-1}$ and $T_{f}=12.92 \mathrm{~h}$. So the ground-based wave period $T_{\mathrm{g}}=7.5 \mathrm{~h}$ is of the same order as the inertial period, indicating that the wave may be an inertia-gravity wave, although this is really determined by the intrinsic period which may be longer or shorter than the ground-based period due to Doppler shifting by the background wind. 

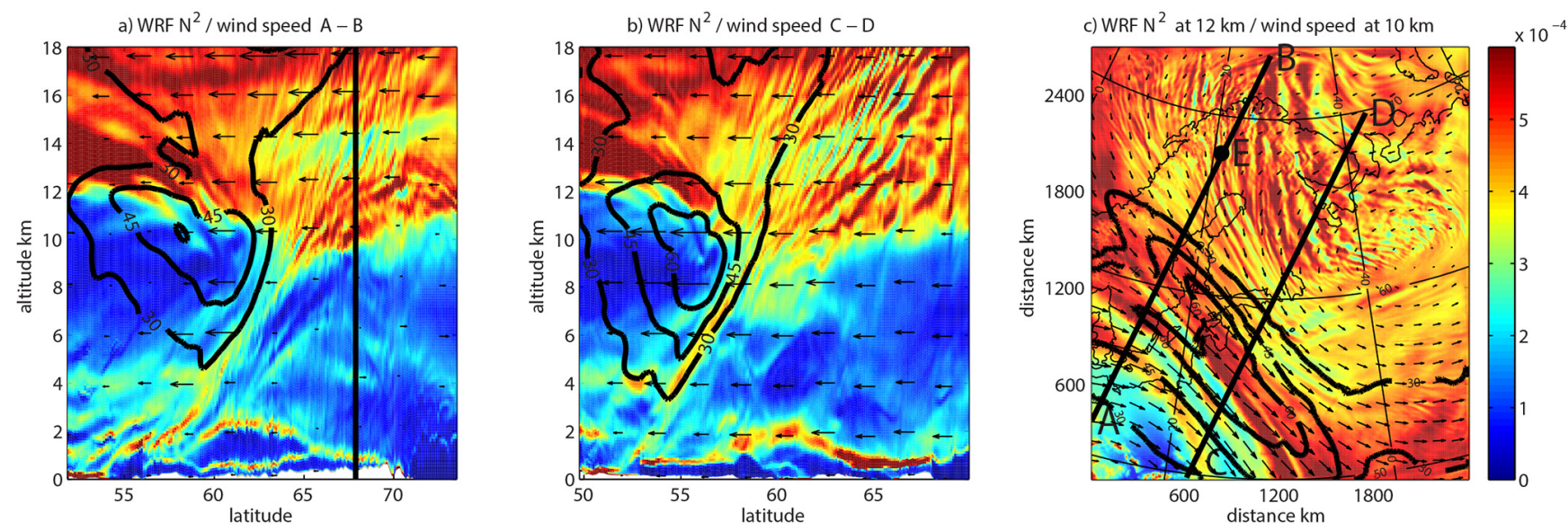

Figure 5. Results from the WRF model for 00:00 UTC on 21 February 2007. (a) Vertical cross section along line A-B in Fig. 5c, vertical black line indicates the radar location. (b) Vertical cross section along line C-D in Fig. 5c. (c) Horizontal cross section for $N^{2}$ at the model level which is at $12 \mathrm{~km}$ altitude at the radar site (marked by a black circle), and for wind at $10 \mathrm{~km}$. Colour scale shows $N^{2}$ (in s ${ }^{-2}$ ). Black contours and arrows show wind speed and direction. In (a) and (b) the arrows show the wind component in the plane of the cross section.
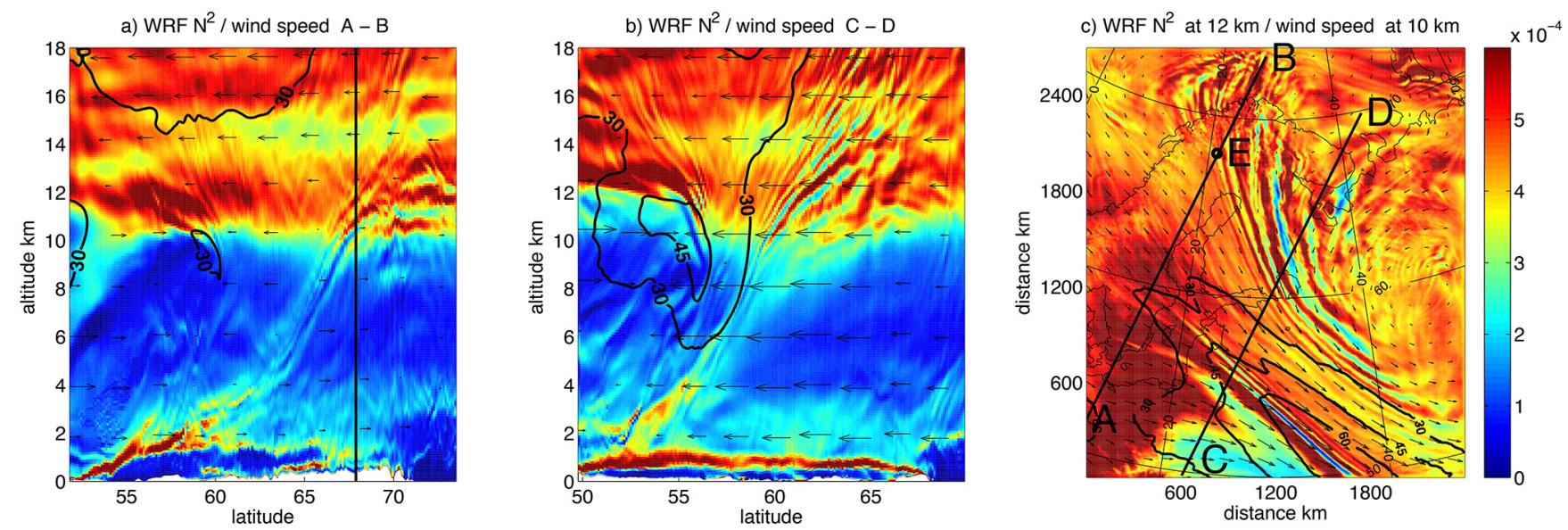

Figure 6. Results from the WRF model as in Fig. 5, but for 00:00 UTC on 22 February 2007.

\subsection{Intrinsic frequency and horizontal wavelengths}

The relationship between intrinsic $\left(\omega_{\mathrm{i}}\right)$ and ground-based $\left(\omega_{\mathrm{g}}\right)$ frequencies is given by

$\omega_{\mathrm{i}}=\left(\omega_{\mathrm{g}}-\boldsymbol{U} \cdot \boldsymbol{k}\right)$,

where $\omega_{\mathrm{g}}$ is the ground-based frequency $\left(2 \pi / T_{\mathrm{g}}\right)$, and $\boldsymbol{U} \cdot \boldsymbol{k}$ is the dot product of the mean background wind vector, $\boldsymbol{U}$, and the wave vector $\boldsymbol{k}$. So, even if we have measurements of $\boldsymbol{U}$, we cannot determine the intrinsic period unless we know $\boldsymbol{k}$.

From the dispersion and polarization relations for hydrostatic IGWs (e.g. Sato et al., 1997) we can write

$\omega_{\mathrm{i}}^{2}=f^{2}+N^{2}(k / m)^{2}$,

$\omega_{\mathrm{i}}=f / R$, where $k=2 \pi / \lambda_{\mathrm{h}}$ and $m=2 \pi / \lambda_{z}$ are the magnitudes of horizontal and vertical wave numbers, respectively, $k^{2} \ll m^{2}$ and $R$ is the ratio of amplitudes of the wind fluctuations along and perpendicular to the direction of wave propagation.

To calculate the intrinsic period, we need to know the magnitude and direction of the wave vector $\boldsymbol{k}$ and the background wind $\boldsymbol{U}$ (Eq. 3), or the ratio of horizontal to vertical wave numbers, $\mathrm{k} / \mathrm{m}$, and the (mean) buoyancy frequency, $N^{2}$ (Eq. 4), or the ratio of wind fluctuations perpendicular and parallel to the direction of propagation $(R$, from the hodogram ellipse, Eq. 5). This is easiest to do for the model results, using Eq. (4). By plotting $N^{2}$ at a fixed height, the horizontal wavelength can easily be determined from the spacing between wave fronts. Using a height of $12 \mathrm{~km}$ (as in Figs. 5 and 6), in the vicinity of the radar site and at the times of radiosonde launches, together with the vertical wavelength as described in Sect. 5.1, to calculate $k / m$, we 

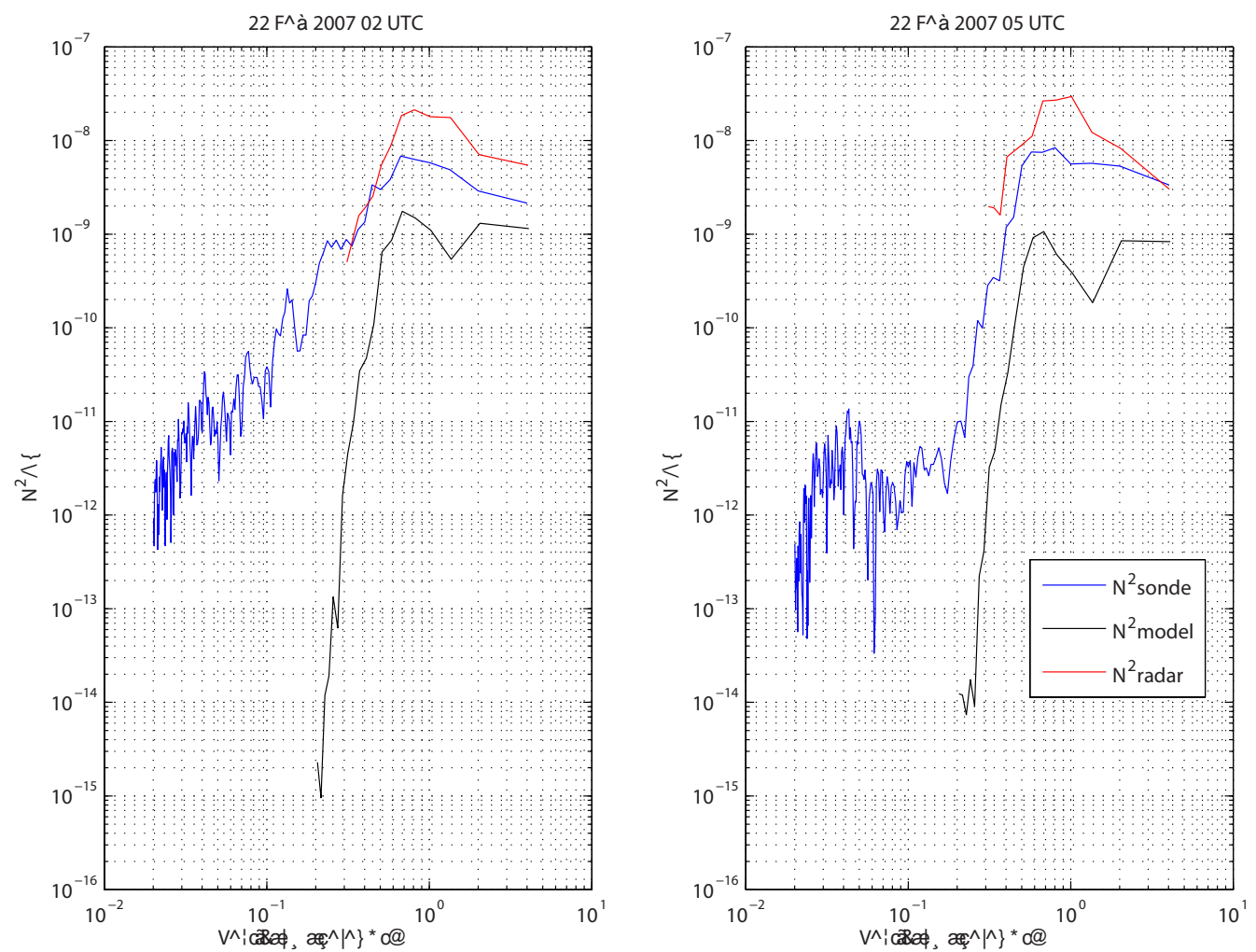

Figure 7. Spectrum of fluctuations of $N^{2}$ in vertical profiles from 10 to $14 \mathrm{~km}$ height, from ESRAD, the WRF model and radiosondes, for the times of two radiosondes, 02:00 and 05:00 UTC on 22 February 2007.

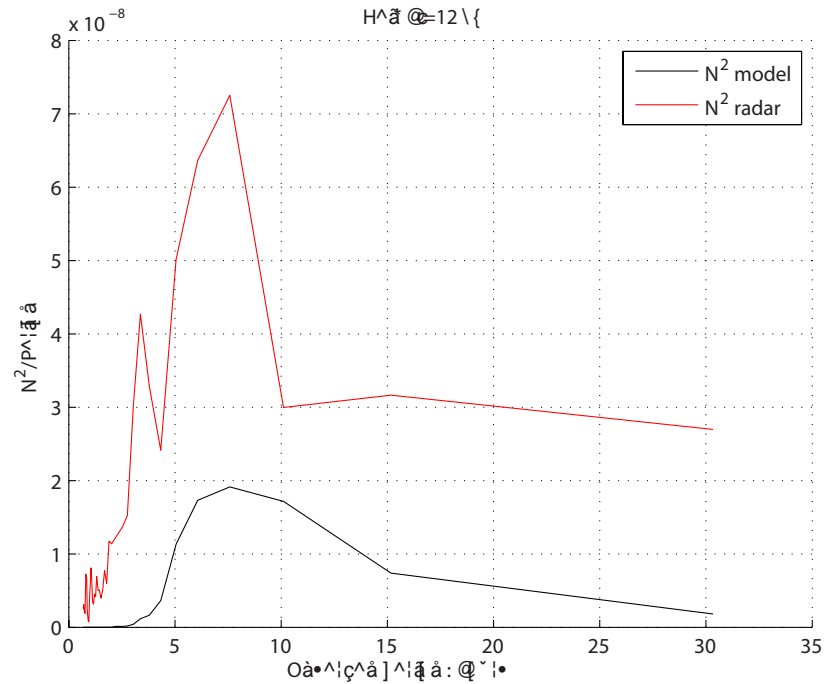

Figure 8. Spectrum of fluctuations of $N^{2}$ for time series at $12 \mathrm{~km}$ height from ESRAD and from the WRF model at the ESRAD location, from 05:00 UTC on 21 February to 09:00 UTC on 22 February 2007. find the intrinsic periods given in Table 1. The orientation of the wave fronts also gives the direction of $\boldsymbol{k}$ (perpendicular to the wave fronts), listed also in Table 1. The intrinsic periods we find, $T_{\mathrm{i}}=2 \pi / \omega_{\mathrm{i}}=6.8-8.9 \mathrm{~h}$, are close to the ground-based period, consistent with the wind direction being close to perpendicular to the direction of wave propagation at $12 \mathrm{~km}$ at the radar location.

For the radiosondes, hodograph analysis and Eq. (5) are used to determine the intrinsic frequency. Figure $9 a$ and $b$ show fluctuations of the temperature and wind in the lower stratosphere (from 10 to $12 \mathrm{~km}$ ) associated with the waves from (a) the five radiosondes and (b) the WRF model data. For these figures, the background winds and temperature gradients have been subtracted (using a third-order polynomial fit for the winds, and a linear fit for the temperature). The altitude range has been chosen in order to have a clear figure and since the structure of the waves (Figs. 1,2) is clearest in this altitude range. Variations of temperature oscillate from -1 to $1^{\circ} \mathrm{K}$, while the absolute variation of wind is about $\pm 3 \mathrm{~ms}^{-1}$ (less for the model). Hodographs have been plotted in the lower panels of Fig. 9a and b. According to the linear theory of GWs, the orientation of the major axis of the ellipse of the hodograph is aligned with the horizontal wave vector of the inertia-gravity wave, and the ratio of the major to the minor axes of the ellipse is proportional to the wave frequency 
(a)
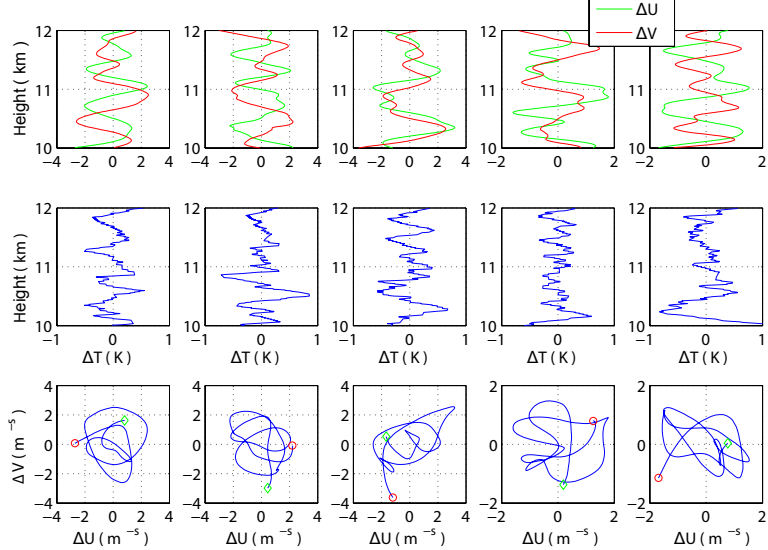

(b)
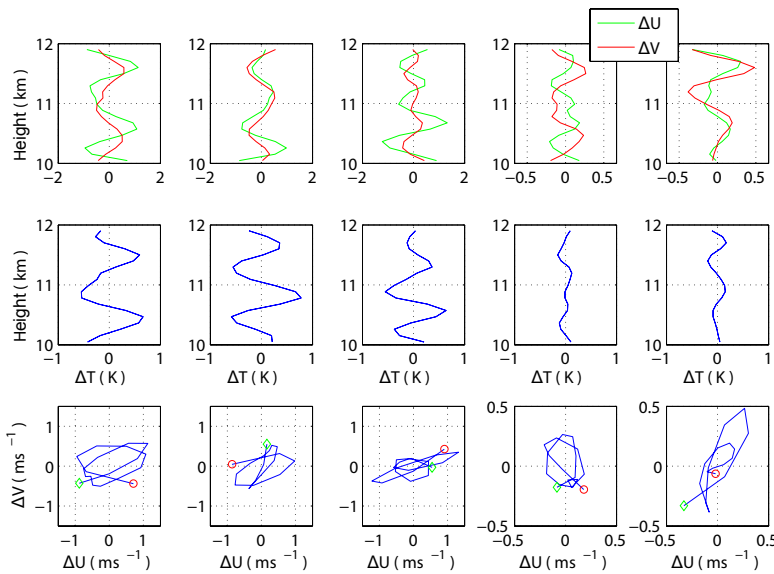

Figure 9. (a) Vertical profile of wind $(U, V)$ and temperature $(T)$ fluctuations from the five radiosondes in Fig. 1, and corresponding hodographs for the wind fluctuations between 10 and $12 \mathrm{~km}$ heights. (b) Vertical profile of wind $(U, V)$ and temperature $(T)$ fluctuations from the WRF data experiment corresponding to the five radiosondes in Fig. 1, and corresponding hodographs for the wind fluctuations between 10 and $12 \mathrm{~km}$ heights. The lowest height $(10 \mathrm{~km})$ of the hodograph is marked by a red circle, the highest $(12 \mathrm{~km})$ by a green diamond.

(Eq. 5). Wave parameters derived by fitting ellipses to the hodograms from the first three sondes are given in Table 1 (note that the direction of $\boldsymbol{k}$ by this method has an ambiguity of $180^{\circ}$ ). For the radiosondes, best fit ellipses have been found by least-squares fitting to intervals of $600 \mathrm{~m}$ (overlapping by $300 \mathrm{~m}$ ) for the entire height range $10-14 \mathrm{~km}$, with mean and standard deviations of the resulting estimates of $\omega_{\mathrm{i}}$ and $T_{\mathrm{i}}$ quoted in the Table. With $\omega_{\mathrm{i}}$ determined by Eq. (5), horizontal wavelength $\lambda_{h}$ can be found using Eq. (4), as also shown in Table 1. There is good agreement between the wave parameters found by the hodograph analysis and those from the model, although the uncertainties are quite large. In some hodographs, the ellipses are nearly circles which makes the uncertainties in determining the direction of the wave vector particularly large.
Further, as described for example in Guest et al. (2000), the linear theory of GWs in a uniform background flow predicts that one vertical wavelength of an upward-propagating inertia-gravity wave traces an elliptical path, which rotates clockwise in the Northern Hemisphere (anticlockwise in the Southern Hemisphere). For a downward propagating wave, the rotation is anticlockwise in the Northern Hemisphere (clockwise in the Southern Hemisphere). The hodograph of the wind between 10 to $12 \mathrm{~km}$ for every radiosonde and the model data shows a clockwise rotation of the wind, most clearly in the first 3 sondes and for the model data corresponding to the two first and two last sondes, which means that the waves are propagating upward in the stratosphere. The downward progression with time of the wavefronts in the radar data (Fig. 1) is also an indication of upward propagation (although it could in principle be misleading if strong wind shear was present, but this is not the case here).

There has been much criticism of the hodograph method. For example, Zhang et al. (2004) simulated a near monochromatic wave of intrinsic frequency $3 f$ using the MM5 mesoscale model, and found that, in a region of background wind shear, although the vertical wavelength could be accurately determined, neither the intrinsic frequency nor the horizontal wavelength could be reliably derived. They further showed how the method breaks down when there is a superposition of waves. One possibility would be to apply bandpass filters to the data to ensure that the hodograph analysis is confined to near monochromatic oscillations, as done by Vaughan and Worthington (2007), but in our cases there was a single dominant vertical wavelength so this should not be a problem. Since the wind in the lower levels around the radar location in the present case comes from the northeast, which is rather flat, we would not expect strong mountain waves and, in any case, any such waves would be cut-off by the change of wind direction at the tropopause. So we can be confident that the wave from the jet-front system was dominant. Plougonven and Teitelbaum (2003) also showed that the hodogram technique has limitations in conditions with strong background wind shear and is only appropriate for a part of the wave spectrum (low frequency, long wave limit). However, in the present cases, at the radar site, the wind shear was weak and the frequency low.

For the radar data, we base our analysis on the method developed by Gubenko et al. $(2008,2011)$. This method assumes that GWs, observed as quasi-sinusoidal fluctuations in a height profile of temperature, density or $N^{2}$, where the amplitude does not grow with height, correspond to the maximum amplitude which can be reached without instability resulting from the wave-induced wind-shear and static stability fluctuations. In this case, there is a relation between the relative amplitude of the wave, and the intrinsic frequency:

$a_{e}=\left[2\left(1-f^{2} / \omega_{\iota}^{2}\right)^{0.5}\right] /\left[1+\left(1-f^{2} / \omega_{\iota}^{2}\right)^{0.5}\right]$, 
where $a_{e}$ is the relative amplitude of the wave, which can be written in terms of $N^{2}$ as

$a_{e}=\left(N_{\max }^{2}-N_{\min }^{2}\right) /\left(N_{\max }^{2}+N_{\min }^{2}\right)$,

where $N_{\max }^{2}$ and $N_{\min }^{2}$ are the maximum and minimum values of $N^{2}$ in the height profile. Once $\omega_{\mathrm{i}}$ has been calculated using Eq. (6), the horizontal wave number can be computed using Eq. (4).

Here, $a_{e}$ is calculated separately for each 20 min averaged profile between 10 and $14 \mathrm{~km}$ heights. A correction factor of 1.1 is applied to account for smoothing out of the extreme values of $N^{2}$ by the relatively poor resolution of the measurements (a Gaussian-weighted height average with width $200 \mathrm{~m}$ ) compared to $\lambda_{z}$. Average values of $a_{e}$ and mean $N^{2}$ over the time interval 00:00 UTC on 21 February and 12:00 UTC on 22 February, and their standard deviation are given in Table 1. These are used together with the vertical wavelength to calculate intrinsic frequency and horizontal wavelength. As can be seen in Table 1, there is good consistency with the wave period and horizontal wavelength from the sondes and from the model. Finally, it is possible to estimate the direction of wave-vector $\boldsymbol{k}$, relative to the background wind using information on mean wind (here available from radiosondes) and Eq. (2). The result is ambiguous as to the sign of the angle with respect to the background wind, so two results are quoted in Table 1. One of these matches well the results from the model and the sondes.

\subsection{Wave amplitude, momentum flux and wave-driven force}

Wave amplitudes in terms of horizontal wind fluctuations $u^{\prime}$ and $v^{\prime}$ (parallel and perpendicular to the direction of wave propagation) have been estimated for the model by examination of the fluctuations between 10 and $14 \mathrm{~km}$ heights at the ESRAD location. For the radiosondes, wind fluctuations are determined from the elliptical fits to the hodograms as described above. For ESRAD, they are calculated (following Gubenko et al., 2008) as

$$
\begin{aligned}
& \left|u^{\prime}\right|=\left(2-a_{e}\right) \lambda_{z} N / 2 \pi, \\
& \left|v^{\prime}\right|=\left(1-a_{e}\right)^{0.5} \lambda_{z} N / \pi .
\end{aligned}
$$

The vertical flux of horizontal momentum in the direction of wave propagation can be estimated as (Fritts and Alexander, 2003)

$F_{\mathrm{ph}}=\rho\left[1-\left(f / \omega_{\mathrm{i}}\right)^{2}\right]\left(u^{\prime} w^{\prime}\right)_{\text {mean }}$,

where $w^{\prime}$ are the fluctuations in vertical velocity, and $\rho$ is the atmospheric density. Substituting the polarization relationship $w^{\prime}=-(k / m) u^{\prime}$, and assuming sinusoidal fluctuations so that $\left(u^{\prime} w^{\prime}\right)_{\text {mean }}=\left|u^{\prime}\right|^{2} k /(2 m)$, this gives

$F_{\mathrm{ph}}=\rho\left[1-\left(f / w_{\mathrm{i}}\right)^{2}\right]\left|u^{\prime}\right|^{2} k /(2 \mathrm{~m})$.
Estimates of the wave amplitudes $\left|u^{\prime}\right|,\left|v^{\prime}\right|$ and $F_{\mathrm{ph}} / \rho$, the momentum flux per unit mass, are given in Table 1 for each method. We can see that there is good agreement between the radiosondes and the radar-based estimates, with $\left|u^{\prime}\right|=2.5-2.7 \mathrm{~ms}^{-1},\left|v^{\prime}\right|=1.3-2.0 \mathrm{~ms}^{-1}$, and $F_{\mathrm{ph}} / \rho=0.03-0.04 \mathrm{~m}^{2} \mathrm{~s}^{-2}$, being consistent with both radiosonde and radar-based estimates. However, the model underestimates the wave amplitude by about a factor 5 , and the momentum flux by at least an order of magnitude.

For comparison with other studies, we can also express the momentum flux, for example at $12 \mathrm{~km}$ height, in absolute terms using $\rho=0.4 \mathrm{~kg} \mathrm{~m}^{-3}$. This yields $F_{\mathrm{ph}}=0.012$ $0.016 \mathrm{Nm}^{-2}(12-16 \mathrm{mPa})$ according to the observations. This is similar to the lower-stratosphere momentum-flux estimates for the corresponding regions (high-latitude winter jetstreams) by Ern et al. (2004), which suggested 10-20 mPa. However, they could only resolve waves with $\lambda_{z}>5 \mathrm{~km}$, so the waves with shorter $\lambda_{z}$ represent an addition to this flux. It is also about an order of magnitude more than the average zonal fluxes suggested to come from wintertime jet-front systems in the gravity-wave resolving model study of Sato et al. (2009), or in the analysis of long-duration stratospheric balloon flights by Vincent et al. (2007). Since the waves identified here are a common occurrence at the radar site, and the model shows that they extend over a large area, they can be expected to make a significant contribution, even in an average sense. Orographic waves over major mountain ranges can contribute an order of magnitude more to the momentum flux when they occur (Alexander and Teitelbaum, 2011; Vincent et al., 2007), but they are probably less common, at least at high northern latitudes.

The amplitudes of the IGWs do not increase with height, rather they are fairly constant (between 10 and $14 \mathrm{~km}$ ). Since reduced density towards higher altitudes would be expected to lead to increased amplitude, this means that they are shedding energy and momentum at a rate which keeps their amplitude constant. Following Sato et al. (1997), this leads to an expression for the wave-driven forces (also referred to as gravity-wave drag) in the direction of wave propagation $\left(F_{\mathrm{h}}\right)$ :

$F_{\mathrm{h}} \sim F_{\mathrm{ph}} /(\rho h)$,

where $h$ is the atmospheric scale height (taken as $7 \mathrm{~km}$ ). For $F_{\mathrm{ph}} / \rho=0.03-0.04 \mathrm{~m}^{2} \mathrm{~s}^{-2}, \quad F_{\mathrm{h}}=0.4-0.5 \mathrm{~ms}^{-1} \mathrm{day}^{-1}$, which represents a significant forcing.

Also shown in Table 1 are estimates of the magnitude of the horizontal phase velocity, $C_{\mathrm{h}},=\omega_{\mathrm{i}} / k$. These show low values, a few metres per second so that the wave will be readily Doppler shifted and distorted by the background wind. For example, according to the model, at 00:00 UTC on 22 February, $\boldsymbol{U} \cdot \boldsymbol{k}$ at $12 \mathrm{~km}$ altitude, just poleward of the jet along $\mathrm{A}-\mathrm{D}$, is between $0 \mathrm{~ms}^{-1}$ (at $65^{\circ} \mathrm{N}$ ) and $-3 \mathrm{~ms}^{-1}$ (at $70^{\circ} \mathrm{N}$ ), while poleward of the jet along $\mathrm{C}-\mathrm{D}$ it is between 0 $\mathrm{ms}^{-1}\left(\right.$ at $\left.60^{\circ} \mathrm{N}\right)$ and $-15 \mathrm{~ms}^{-1}\left(\right.$ at $\left.65^{\circ} \mathrm{N}\right)$. This means that the wavefronts move poleward at the radar location (along A-B), but are almost stationary further to the east, e.g. along 
Table 1. Wave parameters from three different methods. Values in bold are directly estimated from the observed or modelled fluctuations, other parameters are calculated using wave dispersion and polarization relations as described in Sect. 5 . $N_{\mathrm{m}}^{2}$ is mean squared buoyancy frequency, $a_{e}$ the relative amplitude of the wave in $N^{2}, T_{\mathrm{g}}$ the ground based wave period, $\lambda_{z}$ and $\lambda_{\mathrm{h}}$ the vertical and horizontal wavelengths, $\left|u^{\prime}\right|$ and $\left|v^{\prime}\right|$ the amplitudes of the wind fluctuations parallel and perpendicular to the horizontal wave vector $\boldsymbol{k}, \theta$ the direction of $\boldsymbol{k}, f$ the Coriolis parameter, $\omega_{\mathrm{i}}$ the intrinsic frequency, $T_{\mathrm{i}}$ the intrinsic period of the wave, $F_{\mathrm{ph}} / \rho$ the vertical flux of horizontal momentum parallel to $\boldsymbol{k}, C_{\mathrm{h}}$ the horizontal phase speed parallel to $\boldsymbol{k}$. Sonde1/model1 are at 21:00 UTC on 21 February, sonde2/model 2 at $02: 00$ UTC on 22 February, sonde3/model3 at 05:00 UTC on 22 February. All model results for the vicinity of the radar.

\begin{tabular}{|c|c|c|c|c|c|c|c|c|c|c|c|c|}
\hline & $\begin{array}{l}N_{\mathrm{m}}^{2} \\
\mathrm{~s}^{-2}\end{array}$ & $a_{e}$ & $\begin{array}{r}T_{\mathrm{g}} \\
\mathrm{h}\end{array}$ & $\begin{array}{r}\lambda_{z} \\
\mathrm{~m}\end{array}$ & $\begin{array}{r}\left|u^{\prime}\right| \\
\mathrm{ms}^{-1}\end{array}$ & $\begin{array}{r}\left|v^{\prime}\right| \\
\mathrm{ms}^{-1}\end{array}$ & $\begin{array}{r}\theta \\
{ }^{\circ} \mathrm{N} \text { of } \mathrm{E}\end{array}$ & $\begin{array}{r}\lambda_{\mathrm{h}} \\
\mathrm{km}\end{array}$ & $f / \omega_{\mathrm{i}}$ & $\begin{array}{r}T_{\mathrm{i}} \\
\mathrm{h}\end{array}$ & $\begin{array}{r}F_{\mathrm{ph}} / \rho \\
\mathrm{m}^{2} \mathrm{~s}^{-2}\end{array}$ & $\begin{array}{r}C_{\mathrm{h}} \\
\mathrm{ms}^{-1}\end{array}$ \\
\hline Radar & 4.2 & 0.81 & 7.5 & 700 & 2.7 & 1.9 & $33(-125)$ & 113 & 0.68 & 8.8 & 0.03 & 3.4 \\
\hline $10-14 \mathrm{~km}$ & $\pm \mathbf{0 . 3}$ & $\pm \mathbf{0 . 1 0}$ & & $\pm \mathbf{2 0 0}$ & \pm 0.2 & \pm 0.6 & \pm 8 & \pm 48 & \pm 0.17 & \pm 2.2 & \pm 0.01 & \pm 0.7 \\
\hline $0-36 \mathrm{~h}$ & $\times 10^{-4}$ & & & & & & & & & & & \\
\hline Sonde1 & 4.1 & & & 500 & 3.3 & 1.5 & $56(-124)$ & 37 & 0.45 & 5.8 & 0.07 & 1.8 \\
\hline $10-14 \mathrm{~km}$ & $\times 10^{-4}$ & & & & $\pm \mathbf{1 . 5}$ & \pm 0.7 & $\pm \mathbf{3 8}$ & \pm 34 & \pm 0.24 & \pm 3.2 & \pm 0.04 & \pm 0.4 \\
\hline Sonde2 & 4.1 & & & 700 & 2.8 & 1.6 & $82(-98)$ & 78 & 0.59 & 7.7 & 0.04 & 2.8 \\
\hline $10-14 \mathrm{~km}$ & $\times 10^{-4}$ & & & & $\pm \mathbf{0 . 7}$ & \pm 0.4 & \pm 60 & \pm 26 & \pm 0.11 & \pm 1.4 & \pm 0.01 & \pm 0.3 \\
\hline Sonde3 & 4.0 & & & 600 & 3.1 & 1.4 & $42(-138)$ & 46 & 0.46 & 6.0 & 0.06 & 2.2 \\
\hline $10-14 \mathrm{~km}$ & $\times 10^{-4}$ & & & & $\pm \mathbf{0 . 9}$ & $\pm \mathbf{0 . 8}$ & \pm 43 & \pm 49 & \pm 0.27 & \pm 3.5 & \pm 0.03 & \pm 0.5 \\
\hline Model1 & 4.5 & & & 700 & 0.4 & 0.3 & 29 & 100 & 0.69 & 8.9 & 0.002 & 3.1 \\
\hline $12 \mathrm{~km}$ & $\times 10^{-4}$ & & & & & & & & & & & \\
\hline Model2 & 4.2 & & & 700 & 0.5 & 0.3 & 28 & 66 & 0.52 & 6.8 & 0.004 & 2.7 \\
\hline $12 \mathrm{~km}$ & $\times 10^{-4}$ & & & & & & & & & & & \\
\hline Model3 & & & & 550 & 0.5 & 0.3 & 25 & 76 & 0.67 & 8.7 & 0.002 & 2.4 \\
\hline $12 \mathrm{~km}$ & $\times 10^{-4}$ & & & & & & & & & & & \\
\hline
\end{tabular}

C-D. This explains the curvature in the wave fronts seen in the horizontal sections in Figs. 5 and 6.

Finally, we calculate the magnitudes of the vertical and horizontal group velocities, $C_{\mathrm{g} z}$ and $C_{\mathrm{gh}}$, which determine how quickly a wave packet moves away from it's source. In the hydrostatic inertial gravity wave assumption, this is given by

$C_{\mathrm{g} z}=N^{2} k^{2} /\left(\omega_{\mathrm{i}} m^{3}\right)$

$C_{\mathrm{gh}}=N^{2} k /\left(\omega_{\mathrm{i}} m^{2}\right)$.

Using $N^{2}=0.42 \cdot 10^{-3} \mathrm{~s}^{-2}, T_{\mathrm{i}}=8.8 \mathrm{~h}, \lambda_{\mathrm{h}}=113 \mathrm{~km}$ and $\lambda_{z}=700 \mathrm{~m}, \quad C_{\mathrm{g} z} \sim 0.09 \mathrm{~ms}^{-1}$, or $326 \mathrm{~m} \mathrm{~h}^{-1}$, while $C_{\mathrm{gh}}$ $\sim 15 \mathrm{~ms}^{-1}$ or $52 \mathrm{~km} \mathrm{~h}^{-1}$. So it should take about $12 \mathrm{~h}$ for the wave disturbance to travel upwards from its source above the jet around $10 \mathrm{~km}$ height, to the maximum height where it is clearly seen in the observations, around $14 \mathrm{~km}$. In the same time it will have travelled $600 \mathrm{~km}$ horizontally. The group velocity $C_{\mathrm{gh}}$ is greater than the phase velocity, $C_{\mathrm{h}}$ so that the disturbance can propagate poleward even when the groundbased phase velocity is Doppler-shifted to zero by the background wind.

\section{Summary and conclusions}

We have investigated the source of short-vertical-wavelength IGWs in the lower stratosphere over northern Scandinavia using VHF radar, radiosondes and high-resolution nonhydrostatic modelling, for a 2-day period in February 2007. We have used squared buoyancy frequency, $N^{2}$, as the primary variable to illustrate the waves as this can be used for all three methods. All methods find dominating, upward propagating, IGWs over the radar/radiosonde launch site, with vertical wavelength of 500-700 m and intrinsic period of 6-9 h. Horizontal wavelengths in the range $40-110 \mathrm{~km}$ are consistent with all three methods although the uncertainties using radar and radiosondes are large (several tens of kilometres). Radar and radiosonde measurements give similar estimates for amplitude, about $3 \mathrm{~ms}^{-1}$ in wind perturbation along the direction of propagation. The amplitude in the model at the radar location is a factor of 5 less, but higher amplitudes are found at other locations within the same wave packet. The amplitudes observed by the radar and radiosondes give estimates for the vertical flux of horizontal momentum in the range $12-16 \mathrm{mPa}$, which is an order of magnitude higher than estimates of the average for non-orographic-source waves at similar latitudes (e.g. Vincent et al., 2007; Sato et al., 2009). This shows that IGWs of the type identified here, with vertical wavelengths of less than $1 \mathrm{~km}$, even though they will be intermittent, can provide significant contributions to momentum-flux budgets in the lower stratosphere.

The model clearly shows the source of the waves as a jet-front system, with the jet core moving across the southern part of Scandinavia. The waves reaching the radar site 
appear to originate on the upper, poleward/eastward edge of the jet, at about $10 \mathrm{~km}$ altitude, between the latitude of the jet core and the upper-level front which is located about 200$300 \mathrm{~km}$ poleward of the jet core at $10 \mathrm{~km}$ height. Waves with such short vertical wavelengths, emanating from this source region, appear not to have been reported in earlier studies of inertia-gravity wave generation by jet-front systems. Earlier studies of the same parts of jet-front systems (e.g. Plougonven and Snyder, 2007; Lane et al., 2004; Zülicke and Peters, 2008) have reported waves with longer vertical wavelengths $(>1 \mathrm{~km})$, located above the jet core. These waves are also seen in our simulation but they do not propagate to the high northern latitude of the radar site.
High vertical-resolution measurements of $N^{2}$ by the ESRAD radar in northern Sweden often show similar wave signatures to those shown here. In this study, we have used a method proposed by Gubenko et al. (2008, 2011), based on wave saturation assumptions, to derive wave parameters, including intrinsic period, horizontal wavelength and the vertical flux of horizontal momentum, from vertical profiles of $N^{2}$ alone. The agreement found here between wave parameters derived from radar $N^{2}$ profiles and those from radiosondes and modelling show that the method is useful. Given the synoptic context of the waves, it is likely that the direction of the momentum flux will be predominantly towards the northeast. Since almost 10 years of suitable observations are available from ESRAD, it will be possible to make a statistical study of this type of wave, including seasonal variations in the momentum flux. 


\section{Appendix A: Precision of ESRAD measurements}

In order to characterize wave fluctuations, the radar must be able to make measurements with a precision which is better than the expected amplitude of the wave-induced fluctuations. For a single radar pulse from ESRAD, echoes from the upper troposphere and lower stratosphere have much lower power than the background noise, which has contributions from both internal (electronic) and external (interference and galactic) sources. In order to achieve measurable signal levels, echoes from a large number of radar pulses are integrated coherently (i.e. components which are in-phase or in quadrature compared to the initial phase of the transmitted pulse are added separately). This leads to an increase in the signal-tonoise ratio (SNR) by a factor equal to the number of coherent integrations. The number of coherent integrations which can be used depends on the pulse repetition rate (determined by the maximum height coverage needed, typically $30 \mathrm{~km}$ at ESRAD during winter) and on the maximum sampling time which can be used. The maximum sampling time is determined by the application.

For Doppler wind measurements (used for vertical wind at ESRAD), the sampling rate has to be at least twice the maximum Doppler shift expected. Vertical winds up to $3 \mathrm{~ms}^{-1}$ can be expected at the ESRAD location (due to orographic waves), corresponding to a Doppler shift of $1 \mathrm{~Hz}$, requiring maximum sampling times less than $0.50 \mathrm{~s}$. Horizontal winds at ESRAD are measured using the full correlation technique. The relation between sampling time and maximum wind speed which can be measured using this technique has been addressed by Holdsworth and Reid (1995). It can be estimated as

$\Delta T_{\max }=4.8 \lambda /\left(V_{\max } \theta_{\mathrm{eff}}\right)$,

where $\Delta T_{\max }$ is the sampling time, $V_{\max }$ the corresponding maximum wind speed, $\lambda$ the radar wavelength, and $\theta_{\text {eff }}$ the effective angular half-width (in degrees) of the polar diagram of the scatter (including both antenna beam effects and the characteristics of the scatterers). For ESRAD, where $\theta_{\text {eff }}$ is generally dominated by the antenna beam-width, about $2^{\circ}$, this yields $\Delta T_{\max }=0.2 \mathrm{~s}$ for $V_{\max }=75 \mathrm{~ms}^{-1}$, which is a reasonable upper limit for the upper troposphere-lower stratosphere (UTLS). For echo power measurements, used to find buoyancy frequency, longer coherent integration times can be used, limited only by the correlation time of the echoes. For typical UTLS conditions at ESRAD, we find that no increase in SNR is achieved after about $1 \mathrm{~s}$ integration time. So we use integration times of $0.2 \mathrm{~s}$ for wind estimates and $1 \mathrm{~s}$ for echo power.

When fully operational, ESRAD uses six separate receivers, each connected to a separate segment of the antenna array. Since only three receivers/antenna segments are needed to determine the horizontal wind, we can make two independent estimates of the wind (and the other parameters) at each height and time. This gives us the possibility to deter-
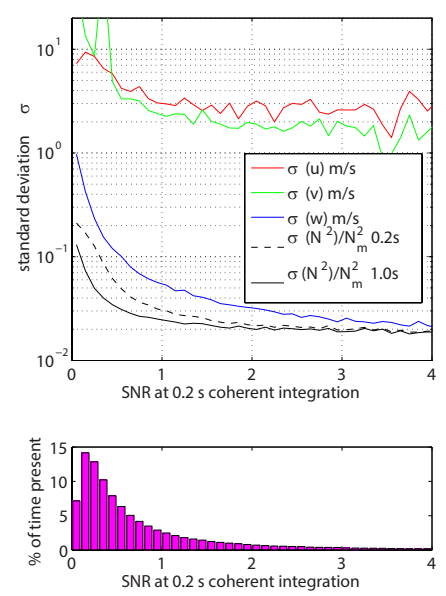

Figure A1. Standard deviation of measured parameters as a function of SNR, and distribution of SNR, for ESRAD using experiment mode fca_150, altitudes $11-13 \mathrm{~km}$ (based on $1 \mathrm{~min}$ data records covering the whole month of April 2009). $u, v$ and $w$ are zonal, meridional and vertical wind components, respectively, using $0.2 \mathrm{~s}$ coherent integration. $N$ is buoyancy frequency. Dashed and solid black lines show results for $N^{2}$ using $0.2 \mathrm{~s}$ and $1.0 \mathrm{~s}$ coherent integration times, respectively.

mine the precision of the measurements from the differences between those pairs of measurements using the statistical relation

$\sigma_{(x 1-x 2)}^{2}=\sigma_{(x 1)}^{2}+\sigma_{(x 2)}^{2}$,

where $\sigma_{(x 1-x 2)}^{2}$ is the variance of the difference between two estimates of the same parameter $\sigma_{(x 1)}^{2}$ which can be assumed equal to $\sigma_{(x 2)}^{2}$, and is the variance in the individual estimates.

Figure A1 shows estimated standard deviations $\sigma$ for parameters which could be used to characterize waves in the UTLS. Results from the analysis of a whole month (April 2009 , when all six receivers were operating) at heights of 11 $13 \mathrm{~km}$ have been used for the estimates. For horizontal winds, is $2-3 \mathrm{~ms}^{-1}$ when $\mathrm{SNR}>1$ but increases to several metres per second for lower SNRs. Since most of the observations in this height region have a lower SNR, this means that waveinduced horizontal wind fluctuations of only a few metres per second cannot be reliably determined. Smaller fluctuations could be detected in vertical winds, down to $0.1 \mathrm{~ms}^{-1}$ at SNR >0.5, which would include about half of the available measurements (assuming that sigma should be less than half the amplitude of the fluctuations to be detected). Wave signatures as small as $20 \%$ in $N^{2}$ could be detected more than $90 \%$ of the time (SNR $>0.1)$.

The waves studied in the current paper have amplitudes of $2-3 \mathrm{~ms}^{-1}$ in horizontal wind components, $0.15-0.30 \mathrm{~ms}^{-1}$ in vertical wind (estimated from the ratio of vertical to horizontal wavelengths) and $80 \%$ in $N^{2}$. This makes observations of $N^{2}$ the most suitable for characterizing the waves using ESRAD. 


\section{The Supplement related to this article is available online at doi:10.5194/acp-14-6785-2014-supplement.}

Acknowledgements. This research has been partly funded by the Swedish Research Council (grants 621-2007-4812 and 621-20103218). ESRAD is maintained and operated in collaboration with the Swedish Space Corporation, Esrange. Particular thanks are due to the Esrange staff for technical support. The authors would like to thank the two reviewers and editor for their constructive suggestions and comments, which we feel improved the manuscript significantly. Thanks also to V. N. Gubenko for his comments on the paper.

Thanks also to the University of Réunion for giving a sabbatical year to the first author.

Edited by: G. Vaughan

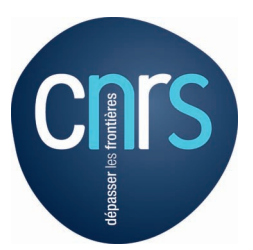

The publication of this article is financed by CNRS-INSU.

\section{References}

Alexander, M. J. and Teitelbaum, H.: Three-dimensional properties of Andes mountain waves observed by satellite: a case study, J. Geophys. Res., 116, D23110, doi:10.1029/2011JD016151, 2011.

Arnault, J. and Kirkwood, S.: Dynamical influence of gravity waves generated by the Vestfjella Mountains in Antarctica: radar observations, fine-scale modelling and kinetic energy budget analysis, Tellus A, 64, 17261, doi:10.3402/tellusa.v64i0.17261, 2012.

Bretherton, C. S. and Smolarkiewicz, P. K.: Gravity waves, compensating subsidence and detrainment around cumulus clouds, J. Atmos. Sci., 46, 740-759, 1989.

Chilson, P. B., Kirkwood, S., and Nilsson, A.: The esrange MST radar: a brief introduction and procedure for range validation using balloons, Radio Sci., 34, 427-436, 1999.

Dörnbrack, A., Birner, T., Fix, A., Flentje, H., Meister, A., Schmid, H., Browell, E., and Mahoney, M.: Evidence for inertia-gravity waves forming polar stratospheric clouds over Scandinavia, J. Geophys. Res., 107, 8287, doi:10.1029/2001JD000452, 2002.

Eckermann, S. D. and Vincent, R. A.: VHF radar observations of gravity-wave production by cold fronts over southern Australia, J. Atmos. Sci., 50, 785-806, 1993.

Ern, M., Preusse, P., Alexander, M. J., and Warner, C. D.: Absolute values of gravity wave momentum flux derived from satellite data, J. Geophys. Res., 109, D20103, doi:10.1029/2004JD004752, 2004.

Fritts, D. C.: Shear excitation of atmospheric gravity waves, J. Atmos. Sci., 39, 1936-1952, 1982.

Fritts, D. C. and Alexander, M. J.: Gravity wave dynamics and effects in the middle atmosphere, Rev. Geophys., 41, 1003, doi:10.1029/2001RG000106, 2003.
Guest, F. M., Reeder, M. J., Marks, C. J., and Karoly, D. J.: Inertiagravity waves observed in the lower stratosphere over Macquarie Island, J. Atmos. Sci., 57, 737-752, 2000.

Gubenko, V. N., Pavelyev, A. G., and Andreev, V. E.: Determination of the intrinsic frequency and other wave parameters from a single vertical temperature or density profile measurement, J. Geophys. Res., 113, D08109, doi:10.1029/2007JD008920, 2008.

Gubenko, V. N., Pavelyev, A. G., Salimzyanov, R. R., and Pavelyev, A. A.: Reconstruction of internal gravity wave parameters from radio occultation retrievals of vertical temperature profiles in the Earth's atmosphere, Atmos. Meas. Tech., 4, 2153-2162, doi:10.5194/amt-4-2153-2011, 2011.

Griffiths, M. and Reeder, M. J.: Stratospheric inertia-gravity waves generated in a numerical model of frontogenesis I: Model solutions, Q. J. Roy. Meteor. Soc., 122, 1153-1174, 1996.

Hei, H., Tsuda, T., and Hirooka, T.: Characteristics of atmospheric gravity wave activity in the polar regions revealed by GPS radio occultation data with CHAMP, J. Geophys. Res., 113, D04107, doi:10.1029/2007JD008938, 2008.

Holdsworth, D. A. and Reid, I. M.: A simple model of atmospheric radar backscatter: descriptionand application to the full correlation analysis of spaced antenna data, Radio Sci., 30, 1263-1280, 1995.

Hong, S.-Y., Dudhia, J., and Chen, S.-H.: A Revised Approach to Ice 10 Microphysical Processes for the Bulk Parameterization of Clouds and Precipitation, Mon. Weather Rev., 132, 103-120, 2004.

Hooke, W. H.: Gravity waves, in: Mesoscale Meteorology and Forecasting, edited by: Ray, P. S., Boston, Amer. Meteor. Soc., 272288, 1986.

Holton, J. R.: An Introduction to Dynamic Meteorology, 3rd Edn., Academic press, 5 International Geophysics series, vol. 48, Academic Press, 551 pp., 1992.

Holton, J. R.: An Introduction to Dynamic Meteorology, 3rd Edn., Elsevier Academic Press, London, 1995.

Kirkwood, S., Belova, E., Satheesan, K., Narayana Rao, T., Rajendra Prasad, T., and Satheesh Kumar, S.: Fresnel scatter revisited - comparison of $50 \mathrm{MHz}$ radar and radiosondes in the Arctic, the Tropics and Antarctica, Ann. Geophys., 28, 1993-2005, doi:10.5194/angeo-28-1993-2010, 2010a.

Kirkwood, S., Mihalikova, M., Rao, T. N., and Satheesan, K.: Turbulence associated with mountain waves over Northern Scandinavia - a case study using the ESRAD VHF radar and the WRF mesoscale model, Atmos. Chem. Phys., 10, 3583-3599, doi:10.5194/acp-10-3583-2010, 2010 b.

Lane, T. P., Doyle, J. D., Plougonven, R., Shapiro, M. A., and Sharman, R. D.: Observations and numerical simulations of inertiagravity waves and shearing instabilities in the vicinity of a jet stream, J. Atmos. Sci., 61, 2692-2706, doi:10.1175/JAS3305.1, 2004.

Lilly, D. K., Nicholls, J. M., Chervin, R. M., Kennedy, P. J., and Klemp, J. B.: Aircraft measurements of wave momentum flux over the Colorado Rocky Mountains, Q. J. Roy. Meteor. Soc., 108, 625-642, 1982.

Lott, F., Kuttippurath, J., and Vial, F.: A Climatology of the gravest waves in the equatorial lower and middle stratosphere: method and comparison between the ERA-40 re-analysis and the LMDzGCM, J. Atmos. Sci., 66, 1327-1346, 2009. 
Morgenstern, O., Giorgetta, M. A., Shibata, K., Eyring, V., Waugh, D. W., Shepherd, T. G., Akiyoshi, H., Austin, J., Baumgaertner, A. J. G., Bekki, S., Braesicke, P., Brühl, C., Chip- perfield, M. P., Cugnet, D., Dameris, M., Dhomse, S., Frith, S. M., Garny, H., Gettelman, A., Hardiman, S. C., Hegglin, M. I., Jöckel, P., Kinnison, D. E., Lamarque, J.-F., Mancini, E., Manzini, E., Marchand, M., Michou, M., Nakamura, T., Nielsen, J. E., Olivié, D., Pitari, G., Plummer, D. A., Rozanov, E., Scinocca, J. F., Smale, D., Teyssédre, H., Toohey, M., Tian, W., and Yamashita, Y.: Review of the formulation of present generation stratospheric chemistry climate models and associated external forcings, J. Geophys. Res., 115, D00M02, doi:10.1029/2009JD013728, 2010.

O'Sullivan, D. J. and Dunkerton, T. J.: Generation of inertia-gravity waves in a simulated life cycle of baroclinic instability, J. Atmos. Sci., 52, 3695-3716, 1995.

Percival, D. B. and Walden, A. T.: Spectral Analysis for Physical Applications: Multitaper and Conventional Univariate Techniques, Cambridge University Press, Cambridge, 1993.

Plougonven, R. and Snyder, C.: Inertia-gravity waves spontaneously generated by jets and fronts. Part I: Diðerent baroclinic life cycles, J. Atmos. Sci., 64, 2502-2520, doi:10.1175/JAS3953.1, 2007.

Plougonven, R. and Teitelbaum, H.: Comparison of a largescale inertia-gravity wave as seen in the ECMWF analyses and from radiosondes, Geophys. Res. Lett., 30, 1954, doi:10.1029/2003GL017716, 2003.

Plougonven, R., Teitelbaum, H., and Zeitlin, V.: Inertia gravity wave generation by the tropospheric midlatitude jet as given by the Fronts and Atlantic Strom Track Experiments radio soundings, J. Geophys. Res. 103, 4686, doi:10.1029/2003JD003535, 2003.

Preusse, P., Eckermann, S. D., and Ern, M.: Transparency of the atmosphere to short horizontal wavelength gravity waves, J. Geophys. Res., 113, D24104, doi:10.1029/2007JD009682, 2008.

Réchou, A., Arnault, J., Dalin, P., and Kirkwood, S.: Case study of stratospheric gravity waves of convective origin over Arctic Scandinavia - VHF radar observations and numerical modelling, Ann. Geophys., 31, 239-250, doi:10.5194/angeo-31-239-2013, 2013.

Rosenthal, A. J. and Lindzen, R. S.: Instabilities in a stratified fluid having one critical level. Part I: Results, J. Atmos. Sci., 40, 509520,1983

Sato, K., O'Sullivan, D. J., and Dunkerton, T. J.: Low-frequency inertia-gravity waves in the stratosphere revealed by three-week continuous observation with the MU radar, Geophys. Res. Lett., 24, 1739-1742, 1997.
Sato, K., Watanabe, S., Kawatani, Y., Tomikawa, Y., Miyazaki, K., and Takahashi, M.: On the origins of mesospheric gravity waves, Geophys. Res. Lett., 36, L19801, doi:10.1029/2009GL039908, 2009.

Shutts, G. J. and Gray, M. E. B.: A numerical modelling study of the geostrophic adjustment process following deep convection, Q. J. Roy. Meteor. Soc., 120, 1145-1178, doi:10.1002/qj.49712051903, 1994.

Skamarock, W. C. and Klemp, J. B.: A time-split nonhydrostatic atmospheric model for weather research and forecasting applications, J. Comp. Phys., 227, 3465-3485, 2008.

Smith, R. B.: The influence of mountains on the atmosphere, edited by: Saltzman, B., Adv. Geophys., 21, 87-230, 1979.

Uccellini, L. W. and Koch, S. E.: The synoptic setting and possible source mechanisms for mesoscale gravity wave events, Mon. Weather Rev., 115, 721-729, 1987.

Vincent, R. A., Hertzog, A., Boccara, G., and Vial, F.: Quasi-Lagrangian superpressure balloon measurements of gravity-wave momentum fluxes in the polar stratosphere of both hemispheres, Geophys. Res. Lett., 34, L19804, doi:10.1029/2007GL031072, 2007.

Vaughan, G. and Worthington, R. M.: Inertia-gravity waves observed by the UK MST radar, Q. J. Roy. Meteor. Soc., 133, 179188, doi:10.1002/qj.142, 2007.

$\mathrm{Wu}$, D. L. and Zhang, Z.: A study of mesoscale gravity waves over the North Atlantic with satellite observations and a mesoscale model, J. Geophys. Res., 109, D22104, doi:10.1029/2004JD005090, 2004.

Wu, X.: Operational Calibration of AVHRR/3 Solar Reflectance Channels, Conference on Characterization and Radiometric Calibration for Remote Sensing, Logan, Utah, August 2004.

Zhang, F.: Generation of mesoscale gravity waves in the uppertropospheric jet-front systems, J. Atmos. Sci., 61, 440-457, 2004.

Zhang, F. Q., Wang, S. G., and Plougonven, R.: Uncertainties in using the hodograph method to retrieve gravity wave characteristics from individual soundings, Geophys. Res. Lett., 31, L11110, doi:10.1029/2004GL019841, 2004.

Zülicke, C. and Peters, D. H. W.: Parameterization of strong stratospheric inertia-gravity waves forced by poleward breaking Rossby waves, Mon. Weather Rev., 136, 98-119, doi:10.1175/2007MWR2060.1, 2008. 